\title{
Malignant Parapharyngeal Tumor with Primary Symptoms of a Temporomandibular Disorder: Review of the Literature and a Case Report
}

\author{
Reda F Elgazzar* \\ Department of Dental Diagnostic and Surgical Sciences, University of Manitoba, Canada
}

Submission: June 07, 2018; Published: June 14, 2018

*Corresponding author: Reda F Elgazzar, Department of Dental Diagnostic and Surgical Sciences, University of Manitoba, 790 Bannatyne Avenue, Winnipeg, Manitoba, Canada, Fax.: 204272 3077, Tel: 204789 3634; Email: reda.elgazzar@umanitoba.ca

Abstract

Objectives: Dysfunctions of the masticatory system are the most frequent causes of the limitations of mouth opening, and the internal derangement of the temporomandibular joints (TMJ) and the craniomyofascial pain are the most common examples of these dysfunctions. A potential problem in dealing with those conditions is the risk of misdiagnosing the rare patient who has a neoplastic disease involving the orofacial tissues. The intent of this article was to review the literature and report a case of a paraphayngeal malignant tumorwhich presented with typical signs and symptoms of a temporomandibular disorder (TMD).

Summary and Conclusion: This case report and the reviewed articles demonstrated that TMDs should not be the only diagnostic category considered in patients with mandibular dysfunction and facial pain. Symptoms caused by a malignant tumour in the head and neck regions may be masked by or mistaken as a concurrent TMD and thus overlooked for a considerable amount of time. Earlier recognition of head and neck cancer by the clinician, with earlier treatment, is essential for improving the generally poor five-year survival rate of this disease. A narrow “TMDoriented' approach may have fatal consequences on the patient life, therefore, the clinician must constantly pursue alternate paths of diagnosis and treatment when a likely cause of the problem is not obvious and/or the patient is refractory to accepted treatment protocols.

Keywords: Temporomandibular Disorders; Pharyngeal Carcinoma; TMJ; Oro Facial Pain; Muscle Contraction; Salivary Glands; Conservative Reversible Therapies; Physiotherapy; Analgesics; Anxiolytic Agents; Occlusal Splints

\section{Introduction}

Temporomandibular disorders (TMDs) are a complex of ailments involving the temporomandibular joints (TMJs), the masticatory muscles, and all associated tissues [1,2]. The signs and symptoms associated with these disorders are diverse, and may include difficulties with chewing, speaking, and other orofacial functions. They also are frequently associated with pain, limited mouth opening and clicking [1]. These symptoms may exist in the absence of significant organic changes in the TMJ, and theories that cite dental occlusion, muscle dysfunction, stress and trauma, as principal causes have been advanced $[3,4]$.The updated guidelines published by The Royal College of Surgeons of Ontario (2009) [1] stressed on that the TMD symptoms may mimic other pain conditions and vice versa, and therefore, it is critical for the practitioner to have an understanding of other causes of oro facial pain in order to diagnose and treat TMD successfully. Common other causes of facial pain may include, but not limited to, the neuralgias (e.g. trigeminal neuralgia, atypical facial pain), demyelinating diseases, CNS tumours, vascular headaches, muscle contraction-type (tension-type) headaches, psychogenic disorders and diseases arising from the dentoalveolar region, sinuses, ear, nose, throat, and salivary glands [1,2]. A decision to treat and how to treat should be based on a detailed and relevant clinical history, a careful clinical examination; an adequate imaging and centered on conservative reversible therapies [1,5]. The patients are often treated successfully by physiotherapy, analgesics, anxiolytic agents, and occlusal splints. However, few patients will not benefit from these treatment modalities and ultimately require surgical intervention such as arthroscopy, arthroplasty, eminectomy, disk repair or diskectomy $[1,2,6]$. In some rare cases, symptoms usually taken to mean uncomplicated TMJ dysfunction may turn out to represent a serious malignant process which is usually primary to a surrounding tissue organ such as parotid gland, ear, nose, jaw, mouth and throat [7-9] or rarely metastasis from a distant organ such as lung [6]. The objectives of this article are to review the literature and report a case ofa paraphayngeal malignant tumourwhich was found to be coincident with and masked by typical TMD signs and symptoms. 


\section{Global Journal of Otolaryngology}

\section{Case Report}

A Fifty two -year-old lady was referred by a medical practitioner for consultation and management of TMD problem which had not responded to conventional treatment for a year. History indicated that she irregularly attended her dentist and reported brief closed locking episode while eating an apple in late 2009; she dates her symptoms after that point. She drinks occasionally and used to smoke half pack a day for the last 30 years. She had sore throat for the last 6 months with no response to conventional treatment. A non-infused CT scan done by her physician, on her joints reported subchondral sclerosisand osteoarthritic changes with no report on any other structures. The patient was seen by the author in the OMS clinic at the Health Science Centre (HSC) on March $22^{\text {nd }}$. Clinical examination revealed right preauricular tenderness which the patient described as if "someone putting a knife", otalgia, sore throat which has been treated for almost 6 months, limitation in mouth opening $(30 \mathrm{~mm})$ and right side TMJ clicking on opening and closing and no palpable lymphadenopathy. Panoramic X-ray showed partially edentulous and apparently normal maxilla and mandible as well asosteo-artheritic adaptation of booth TMJ condyles. Intraoral examination showed most of the maxillary teeth was missing and there was only occlusion on some of the anterior teeth. The patient had fair oral hygiene, chronic gingival and periodontal inflammation related to most of the remaining teeth. Most importantly, a slight redness, roughness and induration were noticed on the right palatoglosus foldarea (Figure 1a). A head and neck CT scan and MRI for the TMJ was ordered on an urgent basis to roll out malignancy and look at the joint meniscus. During the next appointment, there was no change in the patient's signs or symptoms; CT scan (Figure 1b) showed $3.2 \times 2.7 \mathrm{~cm}$ parapharyngeal space mass arising from the right tonsillar base and involving the right pterygoid muscles. The MRI scan showed slight anterior disc displacement and nonremarkable findings (Figures 2a \& 2b).

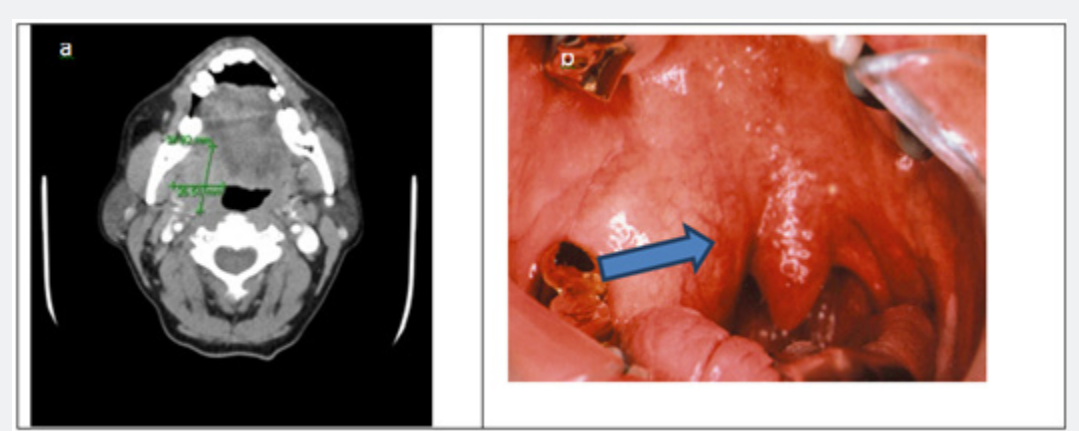

Figure 1: Pre-treatment axial CT (a) section shows T4 mass occupying the right parapharyngeal space, Pre-treatment intraoral photo (b) showing pulging of the right pharyngeal wall medially (arrow).
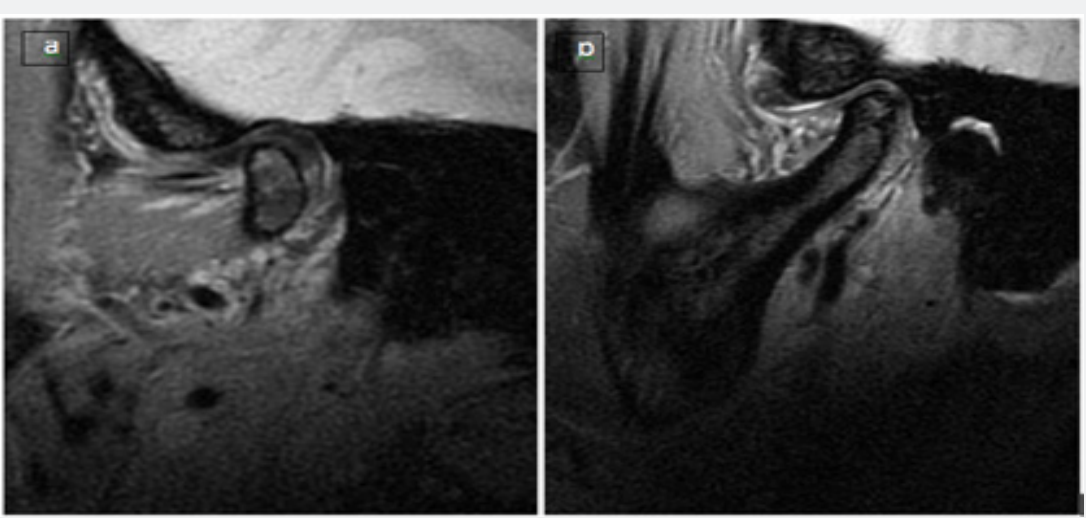

Figure 2: Sagittal, MRI (T1) with mouth opened (a) and closed (b), on the right TMJ showing minimal disc displacement, and non-remarkable structural joint deficits.

On the basis of these findings and the absence of signs and symptoms of acute inflammation, a provisional diagnosis was made as a query right parapharyngealcarcinoma. Without further delay, the patent was referred to the head and neck cancer care for further assessment \& management. The patient was seen by ENT specialist, at HSC, on May $28^{\text {th }}$ who planneda panendoscopy \& an incisional biopsy which have been performed on June $9^{\text {th }}$. The pathological report showed squamous cell carcinoma. The patient was then reviewed on July $15^{\text {th }}$ by the tumor conference and a consensus was made of a diagnosis of T4N0 with a treatment plan of radical radiotherapy and adjuvant chemotherapy. The patient has completed her course of chemo/ radiotherapy on September $17^{\text {th }}$ and according to the reports received from the involved chemo/radiotherapy physicians, 
dated November $18^{\text {th }}$, she was doing very well and started to eat normally; her last CT \& MRI imaging showed complete response to the treatment with no evidence of disease (Figures 3a \& 3b). Therefore, they decided to follow up on the patient with no further intervention. It seems that the original TMD symptoms have either disappeared or became a little issue compared to her newly discovered malignancy.

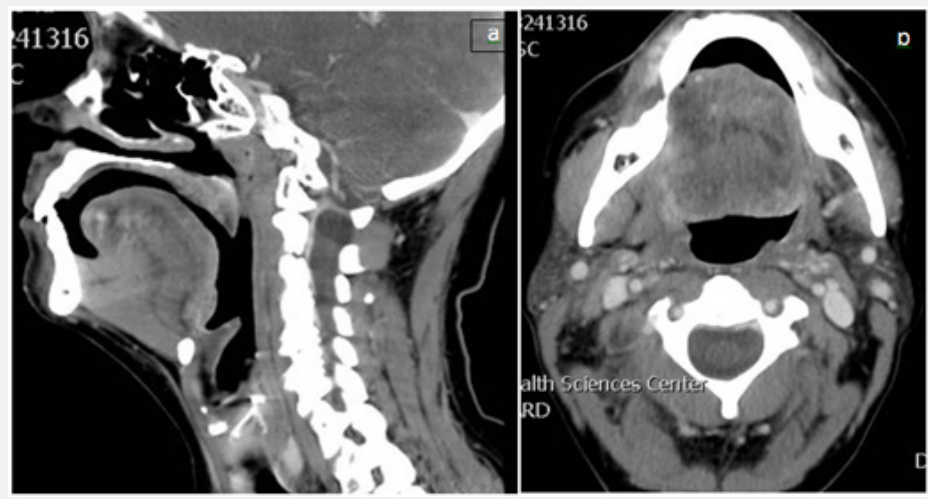

Figure 3: Sagittal (a) \& Coronal (b) CT scan sections after completion of a full course of chemo/radiotherapy; images show complete response to the treatment with no evidence of disease.

\section{Discussion}

TMDs, unfortunately, are not a well-defined clinical entity. Instead they are referred to as «a collection of medical and dental conditions affecting the temporomandibular joint (TMJ) and/or the muscles of mastication, as well as contiguous tissue components $[1,2]$. The diagnosis of specific subentities of TMDs still relies predominantly on the patient's complaints and clinical findings. However, these classical signs and symptoms are not pathognomonic for TMDs, as they may also be associated with a variety of other conditions such as malignant neoplasms $[4,10]$. Neoplasms as an underlying cause of symptoms from the TMJ are rare but well known in the literature. Maxillofacial squamous cell carcinomas [12] pharyngeal and nasopharyngeal tumours $[4,10-13]$ are the most frequent. Adenoid cystic carcinomas and mucoepidermoid carcinomas arising from salivary glands are not uncommon [4,9]. Synovial cell sarcoma3 and metastatic tumors particularly from the lung15have also been reported.

The importance of being early in the detection of head and neck cancer cannot be over-emphasised as diagnosis of early cancer preserves life. Some reports 12 highlighted the possible causes for the delay in the diagnosis of head and neck cancer, of these, is the misdiagnosis made by the clinician, particularly when cancer is not suspected. Other studies indicated that the late presentation and diagnosis and subsequently the late treatment, is considered to be one of the reasons for a low 5 -year survival rate in the head and neck cancer patients $[14,15]$. Trumpy and Lyberg [4] reported 3 patients with TMD signs and symptoms caused by 3 different neoplasms involving the infra temporal space, nasopharynx and the parotid gland. All their presented patients belonged to the age group 25-45 years where TMJ dysfunction is common. The three patients were initially treated according to accepted principles for conservative treatment including occlusal splints and physiotherapy, and followed at a later stage by diskectomy. The authors reported some atypical signs and symptoms, which are not characteristics of TMDs and were not given appropriate concern in due time. These included: persistent, dull, aching facial pain 24 hours a day in one of the cases, numbness in the trigeminal area in another case and persistent and increasing trismus due to involvement of the pterygoid muscles in the third case.

In the current report, the main striking atypical signs and symptoms that led us to think about another origin for the patients TMD complains include:

a) The patient age, which is 52 years, was slightly higher than the normal age range of the TMD patients which is 2545 years.

b) The rough and slightly enduratedpalatoglosus fold.

c) Trismus and sore throat which were long standing and non responding to medical treatment.

d) Failure of the conservative measures to treat or improve the TMD signs and symptoms for almost 12 months.

Based on the data presented in the current and previous reports $[1,2,8]$ several features that may help the clinician to differentiate a TMD condition from a neoplasm in a patient who complains of facial pain can be summarized as follows:

a) Neurologic signs, such as numbness in the distribution of the trigeminal nerve or facial nerve deficits.

b) Lack of improvement or deterioration in the singes and symptoms despite several treatment attempts.

c) Ear, nose, mouth orthroat persistent signs and symptoms such as bleeding, constant pain, trismus, ulceration, change in color, sore through, dysphasia, drainage 
from the ear or deviation of the soft palate or the pharyngeal folds.

d) The presence of intra- or extra-oral swellings including lymphadenopathy and salivary glands enlargement.

e) Unexplained weight loss.

During the course of TMD management, if the decision is made to begin with conservative treatment such as, analgesics, muscle relaxants, physiotherapy and others, it is mandatory that the clinician evaluate the success of this treatment. Trumpy and Lyberg [4] recommend that the patient has to be reexamined and if increasing trismus and pain are encountered, a pan endoscopy, CT and/or MRI scanson the head and neck are recommended to establish a proper diagnosis [16].

\section{Summary and Conclusion}

This case report and the reviewed articles demonstrated that TMDs should not be the only diagnostic category considered in patients with mandibular dysfunction and facial pain. A narrow 'TMD-oriented' approach may have fatal consequences on the patient life. All practitioners who treat TMD patients have to maintain a high index of suspicion when treatment fails to eradicate the patient's complaints. They should give an adequate consideration for the presence of other possible sources of the symptoms and signs in order to facilitate subsequent referral to and management by a qualified medical specialist.

\section{References}

1. (2009) Diagnosis \& management of temporomandibular disorders \& related musculoskeletal disorders. Guidelines of the royal college of surgeons of Ontario, revised version. At the official Website of the royal college of surgeons, Ontario.

2. Greene CS, Klasser GD, Epstein JB (2010) Revision of the American association of dental research's science information statement about temporomandibular disorders. CJ Can Dent Assoc 76: a115.

3. Brown WA (1980) Internal derangement of the temporomandibular joint: review of 214 patients following meniscectomy. Can J Surg 23(1): 30-32.
4. Trumpy IG, Lyberg T (1993) Temporomandibular joint dysfunction and facial pain caused by neoplasms: Report of three cases. Oral Surg Oral Med Oral Pathol 76(2): 149-152.

5. Moen k, Hellem SO, Geitung JT, Skartve L (2010) A practical approach to interpretation of MRI of the temporomandibular joint. Acta Radiol 51(9): 1021-1027.

6. Tabib R, Elias S, Tal Y, Ben-Yehuda A, Abu-Tair J (2010) Temporomandibular joint-related symptoms as initial presentation of lung carcinoma in a patient with takayasu's arteritis. J Oral Maxillofac Surg 69(1): 226-229.

7. DelBalso AM, Pyatt RS, Bush RF, Hirokawa R, Fink CF (1982) Synovial cell sarcoma of the temporomandibular joint. Arch Otolaryngol 108(8): 520-552.

8. Gobetti JR, Ttirp JC (1998) Fibrosarcoma misdiagnosed as a temporomandibular disorder: A cautionary tale. Oral Surg Oral Med Oral Pathol Oral Radiol Endod 85(4): 404-409.

9. Miyamoto H, Matsuura H, Wilson DF, Goss AN (2000) Malignancy of the parotid gland with primary symptoms of a temporomandibular disorder. J Orofac Pain 14: 140-146.

10. Khan J, Quek SY, Markman S (2010) Nasopharyngeal carcinoma masquerading as TMJ orofacial pain. Quintessence Int 41(5): 387-389.

11. Mackie AM, Epstein JB, Wu JY, Stevenson-Moore P (2000) Nasopharyngeal carcinoma: the role of the dentist in assessment, early diagnosis and care before and after cancer therapy. Oral Oncology 36(5): 397-403.

12. Reiter S, Gavish A, Winocur E, Emodi-Periman A, Eli I (2006) Nasopharyngeal carcinoma mimicking a temporomandibular disorder: a case report. J Orofac Pain 20(1): 74-81.

13. Shaushav SM, Elber E, Strong MS (1976) Occult tumors of the infratemporal fossa. Arch Otolaryngol 102(9): 535-538.

14. Elgazzar RF (2000) A clinico-immuno-histochemical study of oral cancer. University of Dundee 6(1).

15. Holland CS (1985) The early diagnosis of oral carcinoma. Dent Update 12: $419-427$.

16. Ogden GR, Cowpe JG, Green MW (1990) Evidence of field change in oral cancer. Br J Oral Maxillofac Surg 28(6): 390-392.

\section{Your next submission with Juniper Publishers} will reach you the below assets

- Quality Editorial service

- Swift Peer Review

- Reprints availability

- E-prints Service

- Manuscript Podcast for convenient understanding

- Global attainment for your research

- Manuscript accessibility in different formats

( Pdf, E-pub, Full Text, Audio)

- Unceasing customer service

Track the below URL for one-step submission https://juniperpublishers.com/online-submission.php 